\section{History and philosophy of psychology}

Phenomenology and the Science of Behaviour. By Georges Thines. Pp. 174. (Allen and Unwin: London, 1977.) £8.50.

BECAUSE so many books are simply rehashes of others on the same topic a reviewer must now ask himself: need a particular book have been written? George Thines' book is not a rehash job, for it covers many topics in the history and philosophy of psychology of which most self-respecting Anglo-Saxon psychologists are entirely innocent. This is not to say they should be; after all, educated experimental psychologists ought to be aware of epistemological issues, know what is meant by phenomenology, and understand the strengths and weaknesses of Gestalt psychology. All in all, Thines' choice of topics is excellent and their range impressive. It includes, for example, discussions on intentionality, psychoanalysis, dualism and epistemology.

Is there any likelihood, however, that Thines' book will make an inroad into the current robust Anglo-Saxon innocence? His credentials are impressive: he is a Belgian steeped in continental philosophy and experimental psychology and he seems to want to modify the direction of American and British empiricist psychology. But Thines' venture is a difficult one: for a reader asked to change his intellectual habits has to be persuaded that a different point of view is worthwhile. This was Neisser's brief in Cognitive Psychology - a book which made many topics and concepts now current in Anglo-American psychology respectable where before they had been dismissed as too mentalistic. Neisser succeeded brilliantly in persuading psychologists to view their phenomena from an alternative viewpoint because he wrote about their current preoccupations but clarified them from the new vantage point. It is here that Thines is so often weak; he is too abstract and makes little attempt to show that he understands the Anglo-American tradition in psychology and still less does he show that the view from his vantage point would be of help.

Thines' vantage point could illuminate some of the preoccupations this side of the channel but the approach adopted would have to be different. First, there will have to be more of an understanding and respect for our tradition than Thines offers. Second, the treatment of issues will have to be less historical and more concerned with current problems. For example, much of what Thines has to say about intentionality and Brentano could be used to clarify some of the issues which arise in such diverse areas as personality theory, clinical psychology and computer simulation.

William Barnes-Gutteridge

William Barnes-Gutteridge is Lecturer in Experimental Psychology at Stirling University, Scotland.

\section{Machine chess-playing}

Chess Skill in Man and Machine. Edited by Peter W. Frey. Pp. 217. (Springer: New York, Heidelberg and Berlin, 1977.) \$16; DM36.20.

"Why can't a computer be more like a man?"-This technological perversion of Professor Henry Higgins' exasperated outburst must exist in the minds of all those who dabble in machine intelligence. It must also be regarded as the underlying theme of this book, which contains articles concerning the theoretical intentions, and practical outcomes, of those projects which attempt to reproduce human skills in the gladiatorial arena of the chessboard.

Only a few years ago, well informed computer scientists, aware of the nascent explosion in computer hardware capabilities, confidently predicted a masterstrength computer chessplayer by 1978 . The explosion occurred, but the master program exists only in the minds of the optimistic uninformed. The reality, which comes over forcibly from several different accounts in the book, is that the com-

and to draw their own book provides a useful starting point.

Nigel Holloway

Nigel Holloway is Lecturer at the Astronomy Centre, University of Sussex, UK.

\section{Polymer engineering}

Treatise on Materials Science and Technology. Vol. 10: Properties of Solid Polymeric Materials. Parts A and B. Edited by J. M. Schultz. (Academic: New York, San Francisco and London, 1977.) A $£ 31.25$, $\$ 44 ; \mathrm{B} £ 24.50, \$ 34.50$.

THE overall aim of this treatise seems to be to provide a review of currently important topics in materials science and engineering for readers who already have a good background knowledge of physics and materials. Volume 10, parts A and B, deals with polymers and includes reviews of microstructures, rubber elasticity, anisotropic elasticity, glassy polymers, fatigue, electronic and electrical properties, and environmental degradation. All but the first are 50-100 pages long, but the chapter on microstructures by $\mathbf{J} . \mathrm{H}$. Magill is 350 pages long and could almost stand on its own as a book on polymer crystallisation. Starting from a review of the plastics industry and simple polymerisation and characterisation, Magill discusses crystal structures, morphology and kinetics, matters which are the centre of most polymer crystallisation books. The literature is covered to about the end of 1975.

Two sections which are particularly timely are those on structure-property relationships and on polymer processing. Much of the justification for studying synthetic polymers must be in the use of the results for the improvement of the properties of plastics. It has become accepted in industry that new large scale polymers are unlikely to be produced now that most of the available cheap monomers have been tried, so that the obvious places for improvement are by blending and modifying polymers for better properties or improving processing methods. This places much more emphasis than before on materials science and engineering, a trend which has been supported by the Science Research Council in their establishment of a polymer engineering panel.

Most books on polymer structure make relatively little mention of relationships between physical structure and properties, the whole subject being treated almost as a side issue, whereas processing rarely gets discussed at all. One could argue that in the short run we do not so much need more experiments in polymer engineering as more books which try to bring together polymer science and engineering. Magill has made a worthwhile effort in this direction; it is a pity that the volume is so expensive.

Paul Calvert
Paul Calvert is Lecturer in Polymer Science at the School of Molecular Sciences, University of Sussex, UK. 